\title{
An Ultrasonic Tree Trunk Diameter Caliper
}

\author{
B.L. Upchurch ${ }^{1}$, D.M. Glenn', \\ G. Vass', and W.A. Anger ${ }^{3}$
}

Additional index words. cross-sectional areas, tree tape

Summary. A unique sensing system is described using an ultrasonic transducer for measuring tree trunk diameters in the orchard. Trunk diameters were calculated from the time it took sound waves to travel from the transducer to the trunk and back to the sensor. The device was calibrated with objects ranging in diameter from 1.6 (0.63 inch) to $19.0 \mathrm{~cm}$ (7.5 inches). The distance between the transducer and object was reduced as the diameter increased and was highly correlated $(P=0.99)$ with actual diameter. The ultrasonic tree diameter sensor exhibited a mean error of $0.04 \mathrm{~cm}$.

$\mathrm{P}$ lant trunk diameters frequently are measured by the tree, for estry, and ornamental industries as well tree fruit researchers. Current methods for measuring diameters use mechanical and electronic calipers, diameter sticks, and tapes, which are often time-consuming and tedious to operate over long periods. The only record of the measurements are those written manually on an inventory sheet or entered manually into a data-logger. Electronic calipers can be interfaced into a data-logger for automatic entry; however, the jaws of calipers must be engaged manually around the tree (Vigneault et al., 1991). Existing techniques are not very accurate, especially with irregularly shaped diameters.

USDA/ARS, Appalachian Fruit Research Station, 45 Wiltshire Road, Kearneysville, WV 25430.

Reference to company name or product name does not imply approval or recommendation of the product by the U.S. Department of Agriculture to the exclusion of other that may be suitable.

${ }^{1}$ Agricultural Engineer.

${ }^{2}$ Soil Scientist.

${ }^{3}$ Agricultural Research Technician.

${ }^{4}$ Electronic Technician. 
The purpose of this project was to develop a nonmechanical system for measuring plant trunk diameters as a means for estimating cross-sectional area. To estimate the cross-sectional area, two design criteria were identified for the trunk diameter measurement system: 1 ) measure diameters from $1.25 \mathrm{~cm}(0.5 \mathrm{inch})$ to $22.9 \mathrm{~cm}$ (8.5 inches) with an accuracy of $1 \%$; and 2 ) collect and record data without manual entry.

\section{Ultrasonic ranging system description}

Ultrasonic transducers have been used in the pastas noncontact distance measurement sensors (Dance 1975; Hoffstatter, 1984). For example, automatic focusing of cameras has been achieved with ultrasonic ranging systems. Ultrasonic ranging systems use high-frequency sound waves to detect the presence of an object. To measure the distance to an object, the system measures the time for the sound wave to travel from the transmitter to the object and back to the receiver. This time $(t)$ is directly related to the distance traveled and is given by the equation, $t=d / c$, where $d$ is the distance traveled by the sound wave and $c$ is the speed of sound at the temperature the measurement was made. The speed of sound is directly related to air temperature (Shirley, 1989). Therefore, c needs to be adjusted for the temperature at which the measurement was taken. This compensation can be accomplished by using the actual temperature to adjust the speed of sound term, or by standardizing all readings, at a particular temperature, by a standard distance measurement taken at that temperature. For our device, each distance measurement was standardized by the time to travel a standard distance $(26.0 \mathrm{~cm})$ at the operating temperature. Temperature variations caused by convection currents were assumed to be negligible. Alignment between the ultrasonic transducers and the center of the trunk was achieved with a hook-like apparatus (Fig. 1). The horizontal section was constructed from $1.9 \mathrm{~cm}$ (0.75 inch) aluminum C channel. The hook was attached to a hockey stick to allow easy engagement with the tree by the user. The $\mathrm{V}$-shaped notch was pressed against the backside of the tree. This apparatus provided a method for aligning the transmitter and receiver with the approximate center of the trunk. As the diameter of the tree increased, the distance between the tree and ultrasonic sensors decreased. Thermal expansion and contraction of the unit
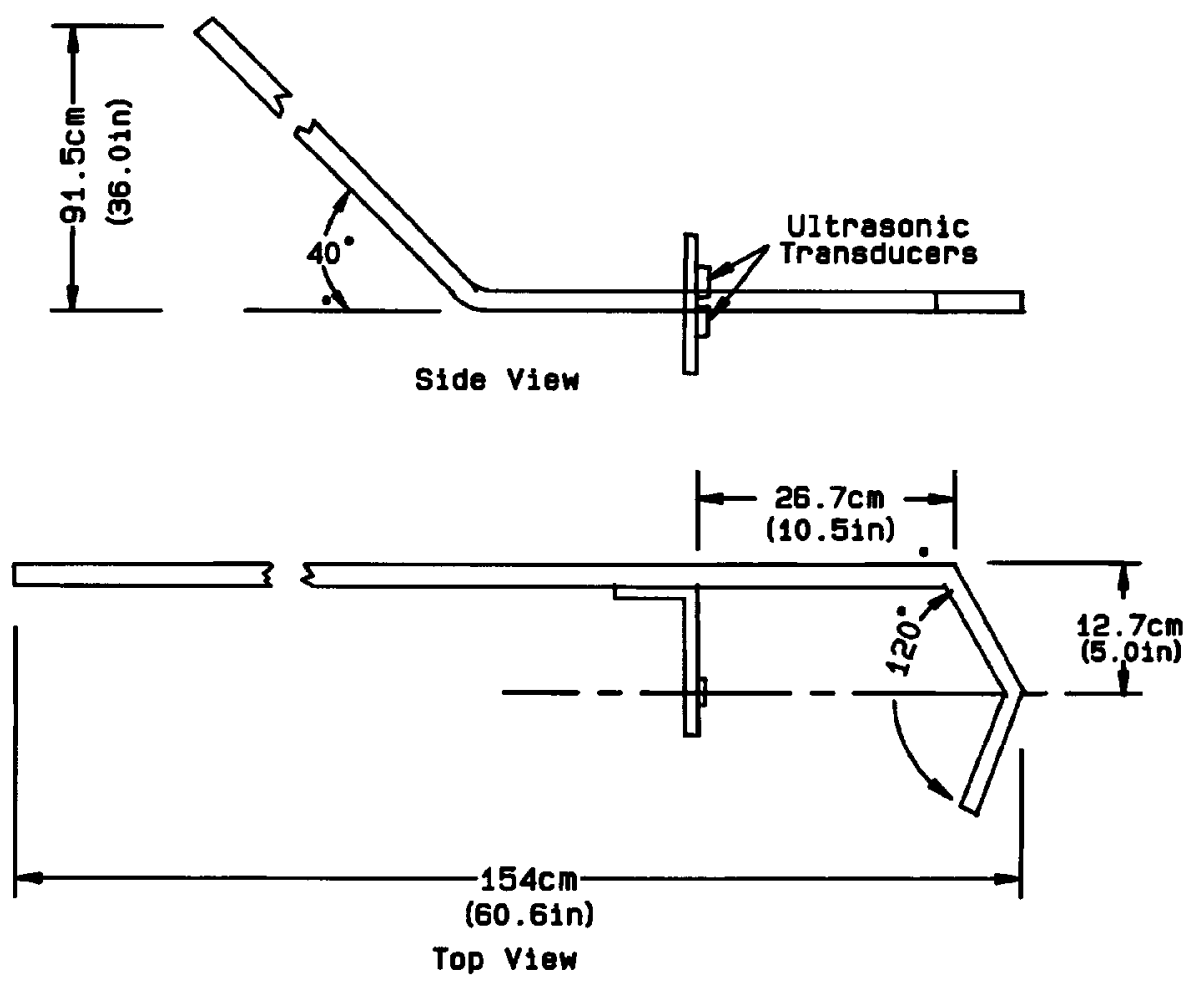

Fig. 1. Diagram of hook-shaped apparatus tried to align the ultrasonic transmitter and receiver with the center of the tree trunk. frame was considered to be negligible.

A block diagram of the electronic timing circuitry is detailed in Upchurch et al. (1992). The output from this circuitry was connected to the digital input of a Polycorder (Omnidata, Model 516B, V 5.1, Logan, Utah), which also is used to store the data. A schematic diagram and Polycorder program are available from us.

\section{Methods and materials}

Calibration was achieved by distance measurements taken on $20 \mathrm{cyl}-$ inders ranging in diameters from 1.6 $\mathrm{cm}(0.6 \mathrm{inch})$ to $19.0 \mathrm{~cm}$ (7.5 inches), over a range of temperatures from $\mathrm{O}$ to $34 \mathrm{C}$ as described by Upchurch et. al. (1992).

The measurement system was tested on 46 peach trees selected at random for size and shape. Two ultrasonic readings were taken for each trunk. If major and minor axes could be identified, the first reading was taken on the major axis and the second reading was taken after rotating $90^{\circ}$ about the trunk. Trunk diameters also were measured with the conventional tree diameter tape. After measuring the trees, the actual cross-sectional area was determined by cutting the trunk through the measurement plane, tracing the boundary of each tree trunk on a piece of paper, cutting the area out, and measuring the tracing area in a leaf area meter (LI-COR, Model L1-3000, Lincoln, Neb.). The major and minor axes for each tree trunk were measured with a caliper and ranged from 5.2 to $13.8 \mathrm{~cm}$ (2 to 5.4 inches). Estimated cross-sectional areas were calculated from the diameter measured by the tree tape and the two diameters from the ultrasonic diameter system. Because two diameters were measured with the ultrasonic unit, an average area was calculated from the two area calculations.

\section{Results}

The ultrasonic unit had a mean deviation of $0.04 \mathrm{~cm}$, with a standard deviation of $0.22 \mathrm{~cm}$ for actual tree trunk measurements. Therefore, a 95\% confidence interval for the mean deviation was- $0.11<\mu<0.01 \mathrm{~cm}$, which was within the desired accuracy. The tree-tape estimate of diameter had a mean deviation of $+0.17 \mathrm{~cm}$, with a standard deviation of 0.19 . The predicted tree area, based on the ultrasonic measurements and the tree tape, 


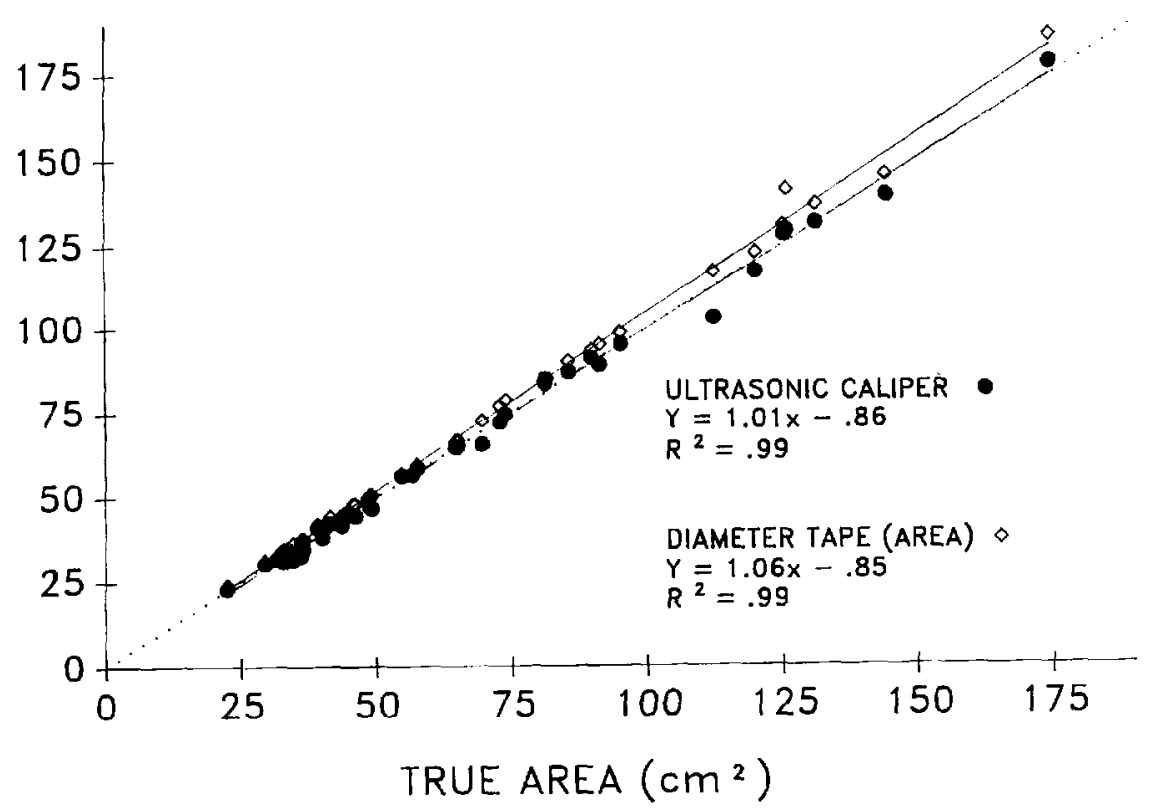

Fig. 2. Comparison of the predicted tree trunk area.from the ultrasonic measurement system, tree tape, and the actual area of 46 tree trunks.

was highly correlated $\left(r^{2}=0.99\right)$ with actual tree trunk area (Fig. 2). The regression equations between the predicted and actual trunk areas demonstrated a significant $(P=0.05)$ overestimation of the area (slope $>1.0$ ) using the tree tape. However, the slope of the regression for the ultrasonic measurement was not significantly different from $1.0(P=0.05)$. The systematic error of the tree tape is due to the non-circular nature of tree trunks, which is addressed adequately by mea-
$<0.001 \mathrm{~cm}$, whale the mean standard deviation was $0.11 \mathrm{~cm}$. Only 16 of the 432 measurements had a deviation $>0.20 \mathrm{~cm}$ from the mean of the six measurements. The largest deviation was $0.51 \mathrm{~cm}$. Large deviations between the predicted and actual trunk diameters occurred on trees that were leaning, which prevented consistent re-alignment.

\section{Summary}

An ultrasonic measuring system was developed for measuring tree trunk diameters and electronically storing the data. The system had an accuracy of $0.04 \mathrm{~cm}$ over an operating temperature range of 0 to $34 \mathrm{C}$.

\section{Literature Cited}

Dance, ].B. 1975. Ultrasonic transmitter/ receiver generates a $20-\mathrm{ft}$ beam that detects objects. Electronic Design 23(16):88.

Hoffstatter, G. 1984. Using the Polaroid ultrasonic ranging system. Robotics Age 6(9):35-37.

Shirley, P.A. 1989. An introduction to ultrasonic sensing. Sensors 6(11):10 17

Upchurch, B.L., W.A. Anger, G. Vass, and D.M. Glenn. 1992. Ultrasonic tree caliper. Applied Eng. Agr. 8(5):711-714.

Vigneault, C., V. Orsat, G. Bourgeois, R.L. Granger, and Y. Groleau. 1991. Tree trunk measuring device. FruitVar. J. 45( 3):170 173. 